\title{
Genetic characterization of the human relapsing fever spirochete Borrelia miyamotoi in vectors and animal reservoirs of Lyme disease spirochetes in France
}

Jean-François Cosson ${ }^{1}$, Lorraine Michelet ${ }^{2}$, Julien Chotte ${ }^{2}$, Evelyne Le Naour ${ }^{2}$, Martine Cote $^{2}$, Elodie Devillers ${ }^{2}$, Marie-Lazarine Poulle ${ }^{3,4}$, Dominique Huet ${ }^{2}$, Maxime Galan', Julia Geller ${ }^{5}$, Sara Moutailler ${ }^{2}$

and Muriel Vayssier-Taussat ${ }^{2^{*}}$

\begin{abstract}
Background: In France as elsewhere in Europe the most prevalent TBD in humans is Lyme borreliosis, caused by different bacterial species belonging to Borrelia burgdorferi sensu lato complex and transmitted by the most important tick species in France, Ixodes ricinus. However, the diagnosis of Lyme disease is not always confirmed and unexplained syndromes occurring after tick bites have become an important issue. Recently, B. miyamotoi belonging to the relapsing fever group and transmitted by the same Ixodes species has been involved in human disease in Russia, the USA and the Netherlands. In the present study, we investigate the presence of B. miyamotoi along with other Lyme Borreliosis spirochetes, in ticks and possible animal reservoirs collected in France.

Methods: We analyzed 268 ticks (Ixodes ricinus) and 72 bank voles (Myodes glareolus) collected and trapped in France for the presence of DNA from B. miyamotoi as well as from Lyme spirochetes using q-PCR and specific primers and probes. We then compared the French genotypes with those found in other European countries.

Results: We found that 3\% of ticks and $5.55 \%$ of bank voles were found infected by the same B. miyamotoi genotype, while co-infection with other Lyme spirochetes (B. garinii) was identified in 12\% of B. miyamotoi infected ticks. Sequencing showed that ticks and rodents carried the same genotype as those recently characterized in a sick person in the Netherlands.
\end{abstract}

Conclusions: The genotype of B. miyamotoi circulating in ticks and bank voles in France is identical to those already described in ticks from Western Europe and to the genotype isolated from a sick person in The Netherlands. This results suggests that even though no human cases have been reported in France, surveillance has to be improved. Moreover, we showed that ticks could simultaneously carry B. miyamotoi and Lyme disease spirochetes, increasing the problem of co-infection in humans.

Keywords: Co-infection, Lyme disease, Bank voles, Ticks

\footnotetext{
* Correspondence: mvayssier@vet-alfort.fr

2INRA, USC Bipar, Anses, 23 Avenue du Général de Gaulle, Maisons-Alfort,

France

Full list of author information is available at the end of the article
} 


\section{Background}

Human pathogenic Borrelia species are comprised of two main groups of spirochetes: the Lyme borreliosis group which cause human Lyme diseases, are widespread throughout Europe, Asia and North America and are transmitted between vertebrates by hard ticks (genus Ixodes) [1]; and the group causing severe relapsing fever in humans and which are transmitted by both, soft and hard ticks [2]. Borrelia miyamotoi, belonging to the relapsing fever group, is transmitted by the same Ixodes species that also transmits Borrelia species from the Lyme Borreliosis group. B. miyamotoi was isolated for the first time in Japan in 1995 from I. persulcatus ticks as well as from the blood of Apodemus argentus mice [3,4], and over recent decades, it has also been detected in Ixodes ticks in Europe, Russia and the USA [5-7]. The first human cases of B. miyamotoi infection were reported in Russia in 2011 [8], and more recently, human infections have been described in the USA and the Netherlands [9-12].

In Europe, Lyme borreliosis is the most common tickborne disease and is caused by different bacterial species belonging to the Borrelia burgdorferi sensu lato complex. They are transmitted by the tick species which has the most impact on European public health, Ixodes ricinus, and which are hosted by many animal species, like rodents, deer, birds and lizards. In France, over 10,000 new cases of Lyme borreliosis are estimated to occur each year. When there has been a history of tick bites, Lyme disease is commonly assumed, but in some cases there is an absence of diagnostic confirmation. Besides Lyme borreliosis typical cases, diagnosed in its first stage by the presence of an erythema migrans following tick bites and in its later phases by serological tests, a number of patients complain of polymorphic and unspecific clinical symptoms (asthenia, fever, myalgia, etc...), for which the diagnosis is not straightforward [13]. In recent years, unexplained syndromes occurring after tick bite has thus become a very important issue, grown considerably with alternate interpretations of the Lyme disease serology, which has led to considerable unrest between formal institutions of infectious disease and patient associations. The proportion of patients bitten by ticks with unexplained syndromes compared with patients who contracted Lyme disease is difficult to know precisely although it is estimated that 50\% of fever after tick bites are of unknown etiological origin [14]. Unexplained syndromes, which have occurred following tick bites have thus become a very important issue in recent years.

In order to better characterize those tick-borne pathogens that are likely to be involved in unexplained tickborne diseases, we recently generated a global picture of their tick-borne bacteria by analyzing whole transcriptomes of $I$. ricinus ticks. Surprisingly, we identified the unanticipated B. miyamotoi in I. ricinus collected in France [15]. In the present study, our aim was to investigate the presence and prevalence of B. miyamotoi, along with Lyme borreliosis spirochetes, in both their vectors, i.e., I. ricinus, and their possible animal reservoirs (bank voles, Myodes glareolus). We have established that I. ricinus and bank voles are infected with $B$. miyamotoi along with Lyme disease spirochetes, that the same $B$. miyamotoi genotype circulate in both $I$. ricinus as well as in the bank voles and that this genotype is perfectly identical to those described in Western Europe, including those infecting humans [12].

\section{Methods}

\section{Ticks and rodents}

Ticks (268 questing Ixodes ricinus female ticks) and bank voles (72 Myodes glareolus) were collected and trapped in the French Ardennes, an endemic region for rodent-borne hantaviruses, along a transect line of about $80 \mathrm{~km}$ in the course of a study of the epidemiology of Puumala hantavirus [16]. Along this transect, we sampled six sites in forested areas and four sites in fragmented habitats (i.e. hedge network). Animals were killed by cervical dislocation. They were weighed, sexed and dissected. All collected ticks were washed and crushed as previously described [17].

\section{DNA extraction}

Voles genomic DNA was extracted from a piece of spleen using the DNeasy kit (Qiagen) according to manufacturer's instructions with a final elution volume of $100 \mu \mathrm{L}$. Tick genomic DNA was extracted using the Wizard genomic DNA purification kit (Promega) according to manufacturer's instructions with a final elution volume of $50 \mu \mathrm{L}$.

\section{Specific Real-Time PCR for detection and prevalence of Borrelia spp. in ticks and bank voles}

Quantitative real-time PCR was performed to determine the prevalence of $B$. miyamotoi, $B$. afzelii, $B$. burgdorferi sensu stricto, B. garinii, B. valaisiana and B. spielmanii using primers and probes described in [15]. A DNA preamplification step was performed in a final volume of $5 \mu \mathrm{l}$ containing $2.5 \mu \mathrm{l}$ TaqMan PreAmp Master Mix (2X), $1.2 \mu \mathrm{l}$ of the pooled primer mix $(0.2 \mathrm{X})$ and $1.3 \mu \mathrm{l}$ of ticks or rodent DNA, with one cycle at $95^{\circ} \mathrm{C}$ for $10 \mathrm{~min}, 14$ cycles at $95^{\circ} \mathrm{C}$ for $15 \mathrm{sec}$ and $4 \mathrm{~min}$ at $60^{\circ} \mathrm{C}$. After the preamplification PCR, products were diluted 1:20 and stored at $-20^{\circ} \mathrm{C}$ prior to use in $\mathrm{qPCR}$. All fluorogenic probes were synthesized with a 6-carboxy-fluorescein (FAM) reporter molecule attached to the 5' end and a Black Hole Quencher 1 (BHQ1) attached to the 3' end. Real-time Taqman PCR assays were performed in a final volume of $12 \mu \mathrm{l}$ using the LightCycler 480 Probe Master mix (Roche Applied Science, Germany) at a $1 \mathrm{X}$ final concentration, with primers and probes at $200 \mathrm{nM}$ and pre-amplified DNA. Thermal 
A

78

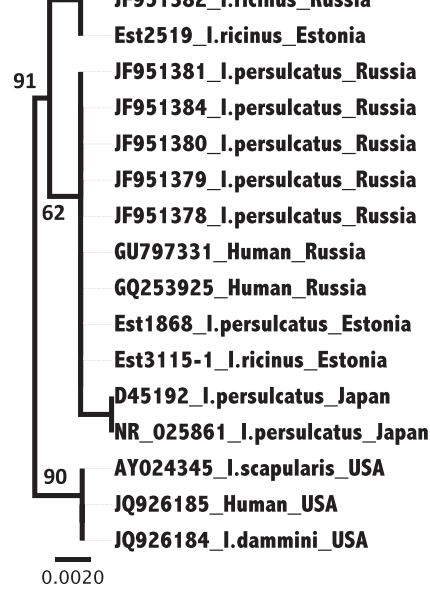

B

tik165_I.ricinus_France_* rodent215_M.glareolus_France_* tik306_I.ricinus_France_* tik84_I.ricinus_France_* tik322_I.ricinus_France_* tik371_I.ricinus_France_* tik404_I.ricinus_France_* tik508_I.ricinus_France_* tik530_I.ricinus_France_* tik279_I.ricinus_France_* tik485_I.ricinus_France_* AF529085_I.ricinus_France KF422751_I.ricinus_Poland KF422750_I.ricinus_Poland KF422749_I.ricinus_Poland GU797338 I.ricinus Russia JF951382_I.ricinus_Russia 2519_I.ricinus_Estonia JF951384 I.persulcatus Russia JF951380_I.persulcatus_Russia rsulcatus Russia Est1868_I.persulcatus_Estonia D45192 I.persulcatus Japan AY024345_I.scapularis_USA

rodent223_M.glareolus_France_* rodent215_M.glareolus_France_* rodent230_M.glareolus_France_* tick508_I.ricinus_France_* tick485_I.ricinus_France_* tick404_I.ricinus_France_* tick371_I.ricinus_France_*

tick322_I.ricinus_France_*

tick306_I.ricinus_France_*

tick279_I.ricinus_France_*

tick194_I.ricinus_France_*

tick530 I.ricinus France *

AB824730_Human_Netherlands

66

AB824855_I.ricinus_Netherlands

Est2519 I.ricinus_Estonia

100 FJ940729_I.persulcatus_Russia

GQ253924_Human_Russia

Est1868_I.persulcatus_Estonia

96 Est3115-1_I.ricinus_Estonia

AY368276_I.persulcatus_Japan

AY922996_I.scapularis_USA
C

tick371_I.ricinus_France_* tick322_I.ricinus_France_* tick404_I.ricinus_France_* tick485_I.ricinus_France_* tick508_I.ricinus_France_* tick84_I.ricinus_France * tick165_I.ricinus_France_* tick194 I.ricinus France * tick279 I.ricinus France * tick306_I.ricinus_France_* tick530_I.ricinus_France_* AB824856_l.ricinus_Netherlands AB824731_Human_Netherlands KF054067_I.ricinus_Switzerland KF054068_I.ricinus_Switzerland KF054069_I.ricinus_Switzerland KF054070 I.ricinus Switzerland

100 Est2519_I.ricinus_Estonia

AY363723_I.ricinus_Sweden Est3115-1 I.ricinus Estonia Est1868_I.persulcatus_Estonia GQ253923_Human_Russia EU635985_I.persulcatus_Russia AY363722_I.persulcatus_Japan AF228023_I.persulcatus_Japan AY363724_I.scapularis_USA
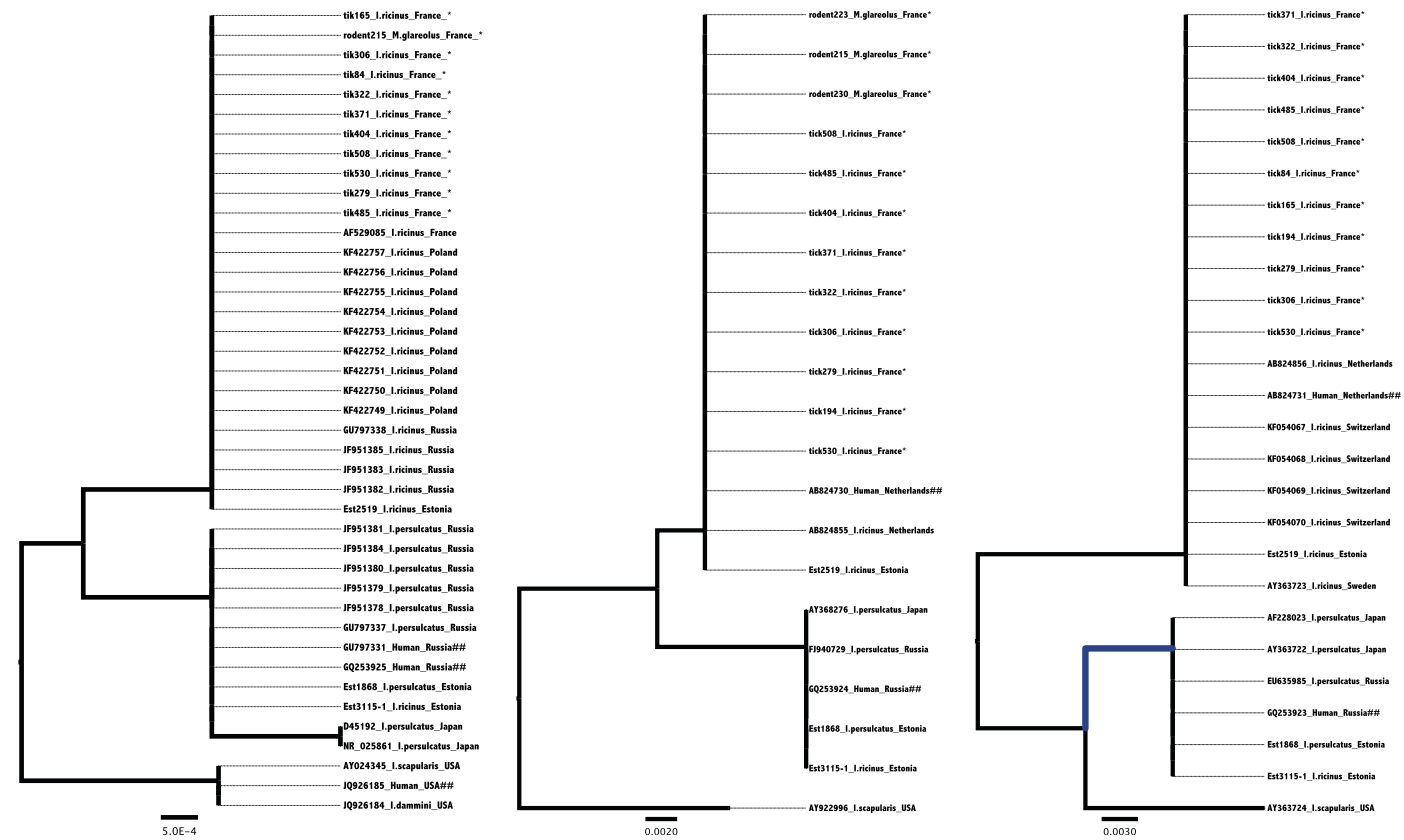

Figure 1 (See legend on next page.) 
(See figure on previous page.)

Figure 1 Phylogenetic trees of B. miyamotoi genotypes based on the partial sequences of A) 16S rRNA (GenBank accession numbers of the French data from KJ412189 to KJ412199), B) glpQ (GenBank accession numbers the French data from KJ425352 to KJ425363) and C) p66 genes (GenBank accession numbers the French data from KJ425364 to KJ425374). Phylogenetic analysis for each of the three genes was performed via the neighbor-joining method and a Kimura 2-parameter distance. Bootstrap analysis was performed on 1,000 replicates. Trees were rooted with Borrelia turicatae and Borrelia ionestari (not shown). Numbers beside branches indicate bootstrap values. Abbreviations: I. for Ixodes, and M. for Myodes. Scale bars indicate Jukes-Cantor evolutionary distances. Samples sequenced in the present study are marked with _**

cycling conditions were as follows: $95^{\circ} \mathrm{C}$ for $5 \mathrm{~min}, 45$ cycles at $95^{\circ} \mathrm{C}$ for $10 \mathrm{~s}$ and $60^{\circ} \mathrm{C}$ for $15 \mathrm{~s}$ and then $40^{\circ} \mathrm{C}$ for $10 \mathrm{~s}$.

\section{Phylogenetic analysis of $B$. miyamotoi genotypes}

Three genomic regions, including partial sequences of $16 \mathrm{~S}$ rRNA (1256 bp), glpQ (379 bp) and $p 66$ (532 bp) genes were amplified and sequenced as previously described [18] from B. miyamotoi positive-testing tick and rodent DNA extracts. Sequence alignment and phylogenetic analysis was performed using SeaView version 4.4.2 as previously described [19].

\section{Ethical approval}

Animals have been treated in accordance with the guidelines of the European Union legislation (Directive 86/609/EEC). The CBGP laboratory has received the approval (no. B 34-169-1) from the regional Head of Veterinary Service (Hérault, France), for the sampling and killing of rodents and the harvesting of their tissues. Dr Cosson has personally received the agreement "certificat d'autorisation d'expérimenter sur animaux vivants" (i.e. "certificate of authorization to experiment on live animals") (no. C34-105) by the French administration.

\section{Results and discussion}

Tick and bank vole DNA samples were assessed for the presence of $B$. miyamotoi via quantitative real-time PCR using primers and probes described in [15]. The prevalence of B. miyamotoi in ticks and bank voles was 3.0\% (8/ 267 ticks) and 5.55\% (4/72) respectively. The prevalence of B. miyamotoi in ticks was similar to that reported for $I$. ricinus collected from other European countries, which ranged from $0.4 \%$ in Estonia to $3.5 \%$ in Germany $[5,18]$. To our knowledge, this study provides the first estimation of B. miyamotoi DNA prevalence in bank voles. Interestingly, ticks and rodents positive for $B$. miyamotoi were trapped from very diverse terrains within our study site, including large expanses of forest (near Les Woiries, $49.903^{\circ} \mathrm{N}, 4.766^{\circ} \mathrm{E}$; and Renwez, $\left.49.859^{\circ} \mathrm{N}, 4.611^{\circ} \mathrm{E}\right)$, forest patches (near La Cassine, $49.575^{\circ} \mathrm{N}, 4.794^{\circ} \mathrm{E}$; and Elan $49.653^{\circ} \mathrm{N}, 4.766^{\circ} \mathrm{E}$ ) and hedge networks bordering grasslands (near Sauville, $49.545^{\circ} \mathrm{N}, 4.801^{\circ} \mathrm{E}$; Boult-aux-Bois $49.413^{\circ} \mathrm{N}, 4.920^{\circ} \mathrm{E}$ ), also with close proximity to human dwellings in some cases.

In addition to $B$. miyamotoi, we also detected Lyme spirochetes B. afzelii in $7.11 \%$ of ticks and $4.16 \%$ of bank voles, and we also found B. burgdorferi sensu stricto, B. garinii, $B$. valaisiana and B. spielmanii in 1.87\%, 9.74\%, 5.24\% and $1.12 \%$ of ticks respectively. Co-infection between $B$. miyamotoi and B. garinii, was noted in one tick (corresponding to $12.00 \%[1 / 8]$ of B. miyamotoi-infected ticks).

$B$. miyamotoi has previously been isolated from the blood of different rodent species such as the small Japanese field mouse (Apodemus argentus) from Japan [3], and the white-footed mouse (Peromyscus leucopus) from the USA [6], all of these species are likely potential B. miyamotoi host reservoirs. Our results support the importance of different rodent species in the circulation of $B$. miyamotoi, by adding the bank vole (Myodes glareolus) in the list of potential B. miyamotoi reservoirs in Europe.

In order to better characterize B. miyamotoi genotypes, three genomic regions, including partial sequences of $16 \mathrm{~S}$ rRNA (1256 bp), glpQ (379 bp) and $p 66$ (532 bp) genes were amplified and sequenced as previously described [18] from positive-testing tick and rodent DNA extracts. All three genes were amplified in all B. miyamotoi positive tick DNA samples, but the $16 S$ RNA gene was amplified in four B. miyamotoi positive bank vole DNA samples, $g l p Q$ in only three, and the $p 66$ gene was not amplified at all in bank vole DNA samples.

Nucleotide sequence similarity analysis of the three genomic regions (two for the bank vole samples) showed that all B. miyamotoi tick sequences were $100 \%$ identical to those amplified from bank voles (Figure 1), suggesting that the same genotype circulates between I. ricinus and bank voles. Phylogenetic analyses of these three genes were internally consistent with each other and gave strong support to the proposed genetic structuring of B. miyamotoi into three distinct geographic clades of Western Palearctic, Eastern Palearctic and Nearctic respectively (Figure 1). French sequences clustered to those amplified from I. ricinus in Switzerland, the Netherlands, Sweden, Estonia, Poland and the European part of Russia. They also clustered with the strain recently described from the patient in the Netherlands [12]. All of these sequences were clearly separated from a second group, which includes sequences from I. ricinus, I. persulcatus and human blood from Estonia, Russia and Japan. A third group includes sequences generated from ticks and human tissues from the USA. Finally, it is relevant to note that all three of these $B$. miyamotoi genetic groups include strains that are pathogenic for humans. 


\section{Conclusions}

We have established that B. miyamotoi is present in I. ricinus as well as in the bank vole Myodes glareolus, one of the most important sources of blood meals for $I$. ricinus larvae. The genotypes of all B. miyamotoi detected in French ticks and rodents were perfectly identical to genotypes already described in ticks from Western Europe, and to the genotype recently isolated from a sick person in the Netherlands. Thus these findings have important implications for public health especially considering that B. miyamotoi-positive ticks and rodents were collected from different terrains, which were sometimes in close proximity to human dwellings. Up until now, no human cases have been reported in France but our data combined with the recent case of human infection described in the Netherlands suggest that surveillance needs to be improved. Symptoms caused by $B$. miyamotoi could easily be confused with symptoms caused by other pathogens, which are better known by practitioners in our study area, such as Puumala hantavirus or Lyme spirochetes.

In addition, our data suggest that, in the studied area, ticks could simultaneously transmit $B$. miyamotoi and Lyme disease spirochetes (B. garinii in our case) to humans. This raises the problem of co-infection in humans, a poorly studied issue but with strong potential implications and relevance for public health.

Competing interests

The authors declare that they have no competing interests.

\section{Authors' contributions}

JFC and MVT conducted the study, analyzed data, and drafted the manuscript, LM, JC, ED, DH carried out DNA extraction, PCR and RT-PCR. ELN, MC, MLP and MG assisted with data collection, JG assisted with designing the study. All authors read and approved the final manuscript.

\section{Acknowledgments}

This study was partially funded by the EU grant FP7-261504 EDENext and is catalogued by the EDENext Steering Committee as EDENext 209 (http://www.edenext.eu). The contents of this publication are the sole responsibility of the authors and do not necessarily reflect the views of the European Commission. This work was also supported by the Metaprogramme MEM of INRA and the COST Action TD1303 (EurNegVec). We thank Emmanuel Guivier, Nathalie Charbonnel, Yannick Chaval, Anne Xuereb and Alexis Ribas-Salvador who helped with the fieldwork. We also thank the group Tiques et Maladies à Tiques (TMT) of the Réseau Ecologie des Interactions Durables (REID) for stimulating discussion and support.

\section{Author details}

${ }^{1}$ INRA, UMR1062, CBGP, F-34988 Montferrier-sur-Lez, France. ${ }^{2}$ INRA, USC Bipar, Anses, 23 Avenue du Général de Gaulle, Maisons-Alfort, France. ${ }^{3}$ URCA, SFR Cap Santé, PROTAL EA 3800, Reims, France. ${ }^{4}$ URCA, CERFE, 08240 Boult-aux-Bois, France. ${ }^{5}$ National Institute for Health Development, Tallinn, Estonia.

Received: 24 March 2014 Accepted: 2 May 2014 Published: 20 May 2014

\section{References}

1. Franke J, Hildebrandt A, Dorn W: Exploring gaps in our knowledge on Lyme borreliosis spirochaetes-updates on complex heterogeneity, ecology, and pathogenicity. Ticks Tick Borne Dis 2013, 4(1-2):11-25.
2. Platonov AE, Maleev W, Karan LS: Relapsing borrelioses fevers: forgotten and new ones. Ter Arkh 2010, 82(11):74-80.

3. Fukunaga $M$, Koreki $Y$ : The flagellin gene of Borrelia miyamotoi sp. nov. and its phylogenetic relationship among Borrelia species. FEMS Microbiol Lett 1995, 134(2-3):255-258.

4. Fukunaga M, Takahashi Y, Tsuruta Y, Matsushita O, Ralph D, McClelland M, Nakao M: Genetic and phenotypic analysis of Borrelia miyamotoi sp. nov., isolated from the ixodid tick Ixodes persulcatus, the vector for Lyme disease in Japan. Int J Sys Bacteriol 1995, 45(4):804-810.

5. Richter D, Schlee DB, Matuschka FR: Relapsing fever-like spirochetes infecting European vector tick of Lyme disease agent. Emerg Inf Dis 2003, 9(6):697-701.

6. Scoles GA, Papero M, Beati L, Fish D: A relapsing fever group spirochete transmitted by Ixodes scapularis ticks. Vector Borne Zoonotic Dis 2001, 1(1):21-34

7. Fomenko NV, Livanova NN, Borgoiakov V, Kozlova IV, Shulaikina IV, Pukhovskaia NM, Tokarevich KN, Livanov SG, Doroshchenko EK, Ivanov LI: Detection of Borrelia miyamotoi in ticks Ixodes persulcatus from Russia. Parazitologiia 2010, 44(3):201-211

8. Platonov AE, Karan LS, Kolyasnikova NM, Makhneva NA, Toporkova MG, Maleev W, Fish D, Krause PJ: Humans infected with relapsing fever spirochete Borrelia miyamotoi, Russia. Emerg Inf Dis 2011, 17(10):1816-1823.

9. Krause PJ, Narasimhan S, Wormser GP, Rollend L, Fikrig E, Lepore T, Barbour A, Fish D: Human Borrelia miyamotoi infection in the United States. N Engl J Med 2013, 368(3):291-293.

10. Chowdri HR, Gugliotta JL, Berardi VP, Goethert HK, Molloy PJ, Sterling SL, Telford SR: Borrelia miyamotoi infection presenting as human granulocytic anaplasmosis: a case report. Ann Intern Med 2013, 159(1):21-27.

11. Gugliotta JL, Goethert HK, Berardi VP, Telford SR III: Meningoencephalitis from Borrelia miyamotoi in an immunocompromised patient. $N$ Engl J Med 2013, 368(3):240-245.

12. Hovius JW, de Wever B, Sohne M, Brouwer MC, Coumou J, Wagemakers A, Oei A, Knol H, Narasimhan S, Hodiamont CJ, Jahfari S, Pals ST, Horlings HM, Fikrig $\mathrm{E}$, Sprong $\mathrm{H}$, van Oers $\mathrm{MH}$ : A case of meningoencephalitis by the relapsing fever spirochaete Borrelia miyamotoi in Europe. Lancet 2013, 382(9892):658

13. Rizzoli A, Hauffe H, Carpi G, Vourc HG, Neteler M, Rosa R: Lyme borreliosis in Europe. Euro Surveill 2011, 16(27):19906. Review. No abstract available. PMID: 21794218 [PubMed - indexed for MEDLINE]

14. Baumann D, Pusterla N, Peter O, Grimm F, Fournier PE, Schar G, Bossart W, Lutz H, Weber R: Fever after a tick bite: clinical manifestations and diagnosis of acute tick bite-associated infections in northeastern Switzerland. Dtsch Med Wochenschr 2003, 128(19):1042-1047.

15. Vayssier-Taussat M, Moutailler S, Michelet L, Devillers E, Bonnet S, Cheval J, Hebert C, Eloit M: Next generation sequencing uncovers unexpected bacterial pathogens in ticks in western Europe. PLoS One 2013, 8(11):e81439.

16. Guivier E, Galan M, Chaval Y, Xuereb A, Ribas Salvador A, Poulle ML, Voutilainen L, Henttonen H, Charbonnel N, Cosson JF: Landscape genetics highlights the role of bank vole metapopulation dynamics in the epidemiology of Puumala hantavirus. Mol Ecol 2011, 20(17):3569-3583.

17. Reis C, Cote M, Paul RE, Bonnet S: Questing ticks in suburban forest are infected by at least six tick-borne pathogens. Vector Borne Zoonotic Dis 2011, 11(7):907-916.

18. Geller J, Nazarova L, Katargina O, Jarvekulg L, Fomenko N, Golovljova I: Detection and genetic characterization of relapsing fever spirochete Borrelia miyamotoi in Estonian ticks. PLoS One 2012, 7(12):e51914.

19. Vayssier-Taussat M, Le Rhun D, Buffet JP, Maaoui N, Galan M, Guivier E, Charbonnel N, Cosson JF: Candidatus Neoehrlichia mikurensis in bank voles, France. Emerg Inf Dis 2012, 18(12):2063-2065.

doi:10.1186/1756-3305-7-233

Cite this article as: Cosson et al:: Genetic characterization of the human relapsing fever spirochete Borrelia miyamotoi in vectors and animal reservoirs of Lyme disease spirochetes in France. Parasites \& Vectors 2014 7:233. 